\title{
Measurement and Evaluation Methods for Damage of Fibers from Dry Sand Erosion in a Hot Environment
}

\author{
Limin Bao, ${ }^{* 1}$ Dongling Li, Danna Qian, Kiyoshi Kemmochi, ${ }^{* 1}$ and Atsuhiko Yamanaka ${ }^{* 2}$
}

\author{
${ }^{*}$ Faculty of Textile Science and Technology, Shinshu University, 3-15-1, Tokida, Ueda-shi, 386-8567, Japan \\ ${ }^{* 2}$ Research Center, Toyobo Co, Ltd., 2-1-1, Katata, Ohtsu, Shiga, 520-0292, Japan
}

\begin{abstract}
Bag filters of fibrous components are widely used to clean exhaust gas. It is reported that filter damage during dust collection involves erosion wear caused by particle collision. Thus, it is necessary to determine the life of bag filters in a hot environment and to clarify the erosion mechanism of fibrous materials. Experiments and evaluation methods were developed to investigate the erosion of fiber at high temperatures. The experiments involved reproducing the erosion of fibrous materials in various temperatures. Analysis of the relationship between the erosion damage rate of a specimen and the total kinetic energy of particles before colliding indicates the erosion resistance of fibrous materials at various temperatures. Using the suggested damage energy curve, we can evaluate the erosion wear characteristics of fiber under different experiment conditions.
\end{abstract}

KEYWORDS: Dry sand erosion, Solid particle impact, Wear, Fiber, Experiment and estimation of erosion, High temperature

\section{INTRODUCTION}

Currently, reduction of the environmental impact of industrial activities is a major concern of many industries and governments. Bag filters composed of fibrous materials are widely used to remove harmful gasses, dioxins, heavy metals, and dust from garbage incinerators with high efficiency. In addition, bag filters are used for many waste gas processing systems, including industrial waste incinerators. ${ }^{1)}$ Moreover, it is the only method for use in garbage incinerators that is permitted by the Ministry of Health, Labor, and Welfare of Japan. However, when bag filters are damaged by long-term or irregular use, internal drift and harmful gasses flow out of the facility and pollute the peripheral environment.

While bag filter damage results from deterioration of materials due to chemical reactions and high temperature, experiments and investigation indicate that wear damage also results from the collision of particles in waste gas (dry sand erosion). ${ }^{2)}$

In studies of the erosion of structural materials, many results have been obtained from basic studies mainly of metals and inorganic materials such as conducted by Hashimoto et al. over a long time. ${ }^{3,4)}$ Researchers (e.g., Harsha et al. ${ }^{5}$ and Barkoula et al. $\left.{ }^{6}\right)$ have investigated the influence of impact angle, speed, and form of colliding particles, as well as the erosion resistance of matrix resin, for GFRP and CFRP, which are frequently used for industrial applications. While FRP composed of fragile glass fiber and carbon fiber has low erosion resistance, we used super fiber, which is a polymer fiber, to develop FRP with high specific strength and excellent solid particle erosion resistance. ${ }^{7-8)}$ No studies have focused on the erosion of fibrous materials; therefore, many points remain unclarified.

We focused on the erosion of fibrous materials and developed related experiments and evaluation methods and manufactured a prototype of the developed measuring device. Using this device, we reproduced the erosion of fiber and its composites, and measured and evaluated the erosion resistance of fibrous materials and their composites. ${ }^{9)}$ Furthermore, we measured the erosion resistance of various types of fibers used for bag filters and explored their damage mechanisms. We found that polymer fiber with high toughness has better erosion resistance than glass fiber which is a fragile inorganic fiber. ${ }^{9)}$

Many of the bag filters for garbage incinerators and blast furnaces are frequently used in a hot environment. However, no studies have addressed the dry sand erosion of materials in a hot environment; 
therefore, many points remain unclarified.

In this study, we developed experiments and evaluation methods for the dry sand erosion of fiber in a hot environment in order to determine the erosion resistance of fiber and manufactured a prototype of the developed measuring device. Using this device, we reproduced the erosion of fibers, and measured and evaluated the erosion resistance of fibrous materials.

\section{EROSION IN A HOT ENVIRONMENT AND THE MEASUREMENT METHOD}

The method for measuring the erosion resistance of hard materials that utilizes the material's wear volume is not applicable to fibrous materials. Therefore, we proposed a method for evaluating the erosion of fibrous materials that uses the change in strength of fiber and thread with erosion and manufactured a prototype system.9) The erosion of bag filters for garbage incinerators and blast furnaces involves wear damage due to the collision of particles in hot waste gas (Fig. 1), so a high-temperature multiphase flow and a hot environment for fibrous materials are required.

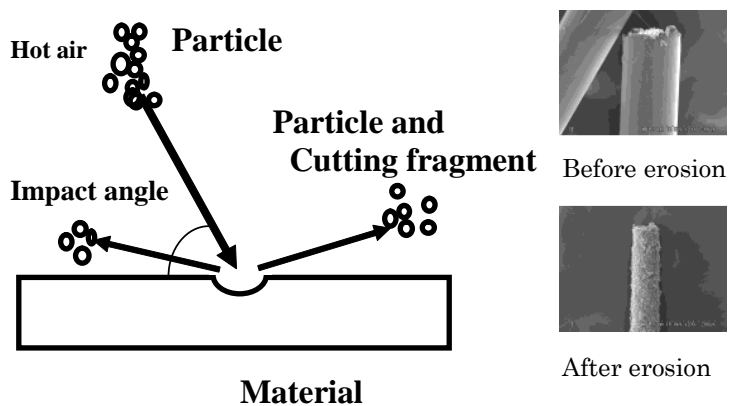

Fig. 1. Schema of erosion at high temperature

Here, we used a conventional erosion measuring device (Fig. 2) and added a device that generates high-temperature multiphase flow (hot air beam, HAB4051, Hakko Co., Ltd.) (Fig. 3). Air compressed by an air compressor is heated by a hot air beam. The air temperature is measured by a thermocouple installed in the hot air beam and controlled through an air controller (HAC2020, Hakko Co., Ltd.). Powder is supplied to the heated air. There is a distance between the heating site and the point of collision with the fiber specimen, so temperature drops are a concern. The preset temperature of the hot air beam controller and the temperature around the fiber specimen were actually measured in order to use them for correcting the temperature settings. Furthermore, a space heater (SH-7, Hakko Co., Ltd.) was installed to stabilize the temperature of the portion where the specimen was placed. The temperature of the metallic board was adjusted to the temperature of the jetted air by utilizing a space heater controller (DG2-100, Hakko Co., Ltd.).

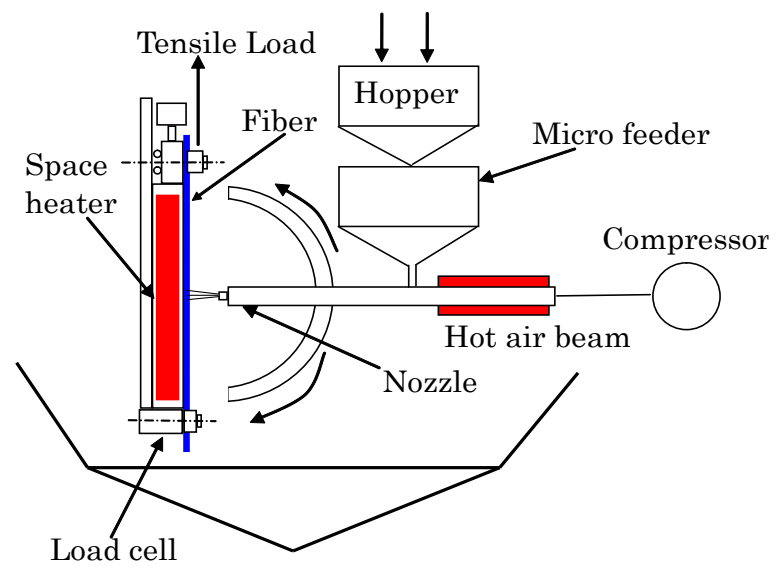

Fig.2 Schematic drawing of the test system for erosion of fibers at high-temperature

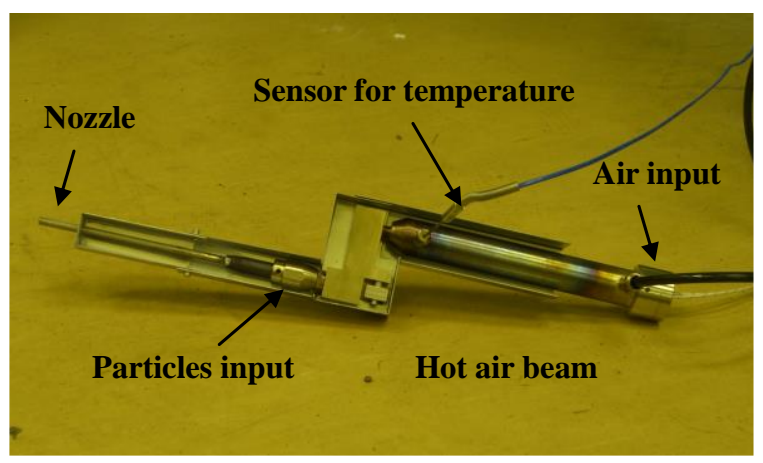

Fig. 3. Sketch map of hot air beam

The experiment procedures are as follows. The ends of the fiber are fastened to the load cell and the electric slider. The portions supporting the fiber are heated to the specified temperature using the space heater, and the air is heated by the hot air beam. After the temperature of the air from the nozzle reaches the specified level, a certain volume per second of powder is jetted from the nozzle and hits the fiber specimen during the specified time length. Powder can be supplied constantly by the micro-feeder. After the preset time has elapsed, the fibrous material damaged by wear is subjected to a tensile test by the electric slider, and its fracture strength is measured with the load cell.

Test conditions are the same as those stated in the 
previous report. ${ }^{9)}$ Poly Tetra-Fluoro-Ethylene (PTFE) fiber made by Toray was used. PTFE has 60 filaments, fiber diameters of $18 \mu \mathrm{m}$, and a yarn count of 440dtex. For comparison, DE-75 fiber (glass fiber) made by Unitika Glass Fiber Co., Ltd., is also used. DE-75 has 800 filaments, fiber diameter of $6 \mu \mathrm{m}$, and a yarn count of 671dtex. Both types of fiber are used for bag filters at the site.

Considering the fly ash in a refuse incinerator plant, white alumina polishing material (mean diameter $11.5 \mu \mathrm{m}$, standard deviation 21.5) from Showa Denko K.K. was used for the particles.

\section{EVALUATION METHOD FOR EROSION IN A HOT ENVIRONMENT}

Figure 4 plots the fiber's fracture strength obtained by conducting a tensile test after jetting hot air for 20min while heating the space heater, using the system in Fig. 2. The horizontal axis represents the testing temperature (the temperature of the space heater and hot air), and the specimen is PTFE fiber. The fracture strength of PTFE fiber, which is a polymer, decreases as the temperature increases.

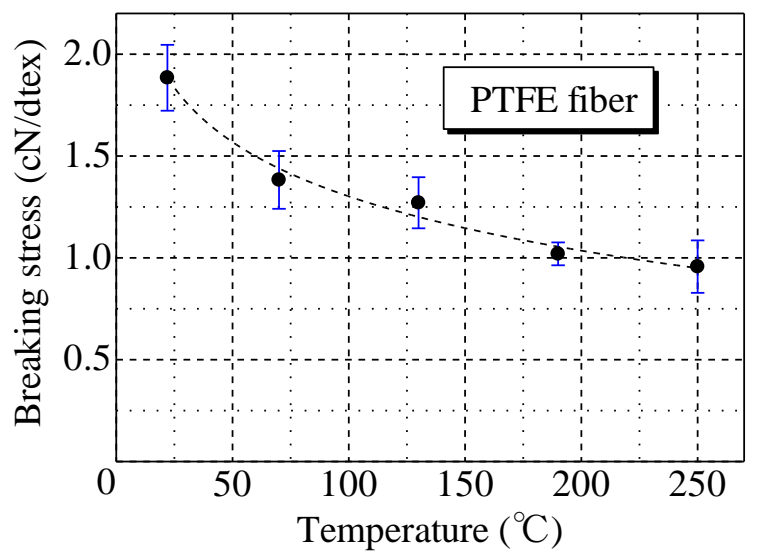

Fig, 4. Breaking stress-temperature curve for FTFE fiber

Using the device depicted in Fig. 2, we investigated the erosion of fiber at a various impact angles, wear times, and temperatures. Figure 5 plots the stress-strain curve of fiber before and after wear. The impact angle is $90^{\circ}$, the wear time is $6 \mathrm{~min}$, and the sample is PTFE fiber. The particle supply rate is $0.816 \mathrm{~g} / \mathrm{min}$, and the collision speed is $80.14 \mathrm{~m} / \mathrm{sec}$. The testing temperature was set to 22 degrees centigrade (room temperature) and 130 degrees centigrade. The maximum stress of the curve was defined as breaking stress. The breaking stress decreased in a hot environment even after the same wear time.

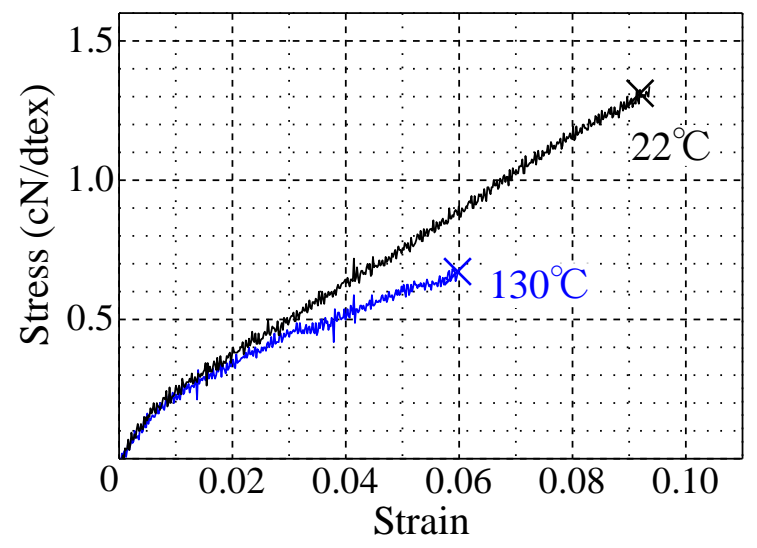

Fig. 5. Stress-strain curve for PTFE fiber (Wear time: 6min, Impact angle: $90^{\circ}$ )

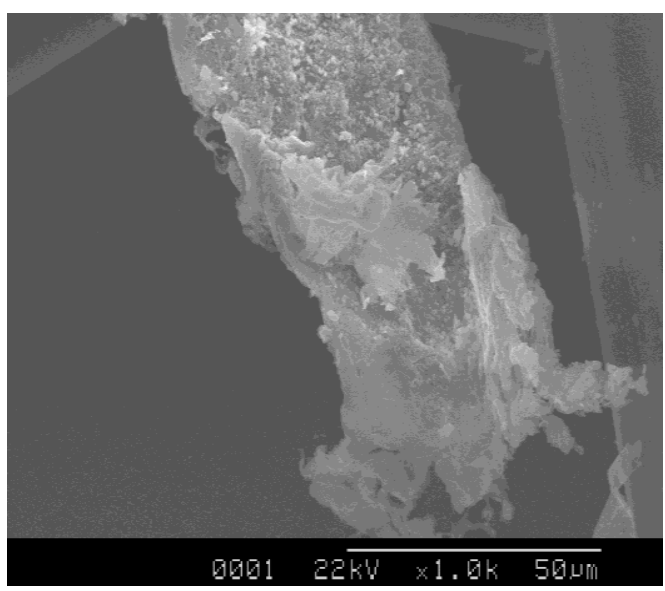

(a) $22^{\circ} \mathrm{C}$

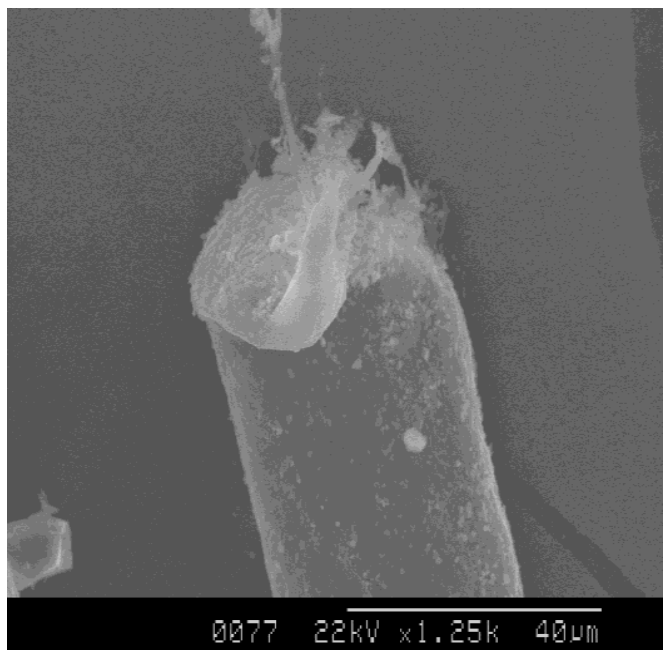

(b) $250^{\circ} \mathrm{C}$

Fig. 6. Photographs of PTFE fibers broken surfaces (Impact angle $90^{\circ}$ ) 


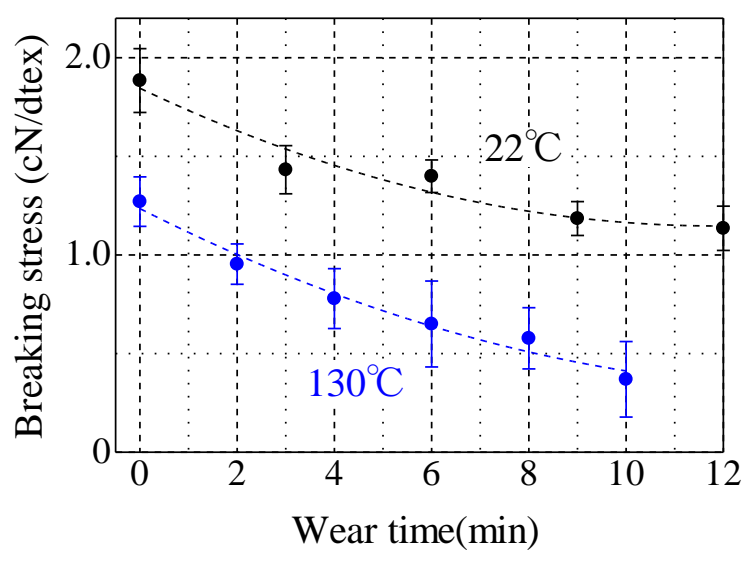

Fig. 7. Wear time-breaking stress curve of PTFE fiber $\left(90^{\circ}\right)$

Figure 6 presents SEM photographs of PTFE fiber after being subjected to erosion at different temperatures and then a tensile test until fracture. The ambient temperature during erosion is room temperature $\left(22^{\circ}\right)$ and $250^{\circ}$, and the impact angle is $90^{\circ}$. PTFE fiber is damaged in the direction of particle impact (Fig. 6(a)). The surface of the fiber is cut, and ductility damage is apparent. As seen in Fig. 6(b), the fracture surface of fiber is melted in a hot environment. We assumed that the strength of the fiber decreased due to softening of the fiber at a high temperature $\left(250^{\circ}\right)$, which caused a decrease in erosion resistance of PTFE fiber in a hot environment.

Figure 7 plots the relationship between wear time and breaking stress of the PTFE fiber. The experiment conditions are the same as in Fig. 5. The experiment was repeated five times. Wear times were $3,6,9$, 12min (22 degrees centigrade), and 2, 4, 6, 8, 10min (130 degrees centigrade). The breaking stress depended on the wear time. A long wear time decreases the fiber breaking stress. The amount of decrease represents material erosion. Breaking stress at 130 degrees centigrade is less than that at room temperature.

Damage is defined as:

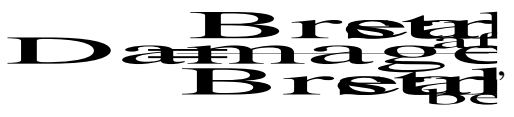

where breaking stress after is the breaking stress after fiber wear, and breaking stress before is the breaking stress before fiber wear.

$\mathrm{We}^{9)}$ investigated the erosion characteristics of fiber using the sum of kinetic energy of particles before colliding with the fiber (kinetic energy of impact: $W_{E}$ ) expressed as

$$
\text { Wat-F/2t }\left(\mathrm{J} / \mathrm{m}^{2}\right)
$$

where $V$ is impact speed $(\mathrm{m} / \mathrm{sec}), t$ is wear time $(\mathrm{sec})$, A is the true contact area of the particle $\left(\mathrm{m}^{2}\right)$, and $\rho$ is the rate of particle supply by the micro-feeder $(\mathrm{g} / \mathrm{sec})$.

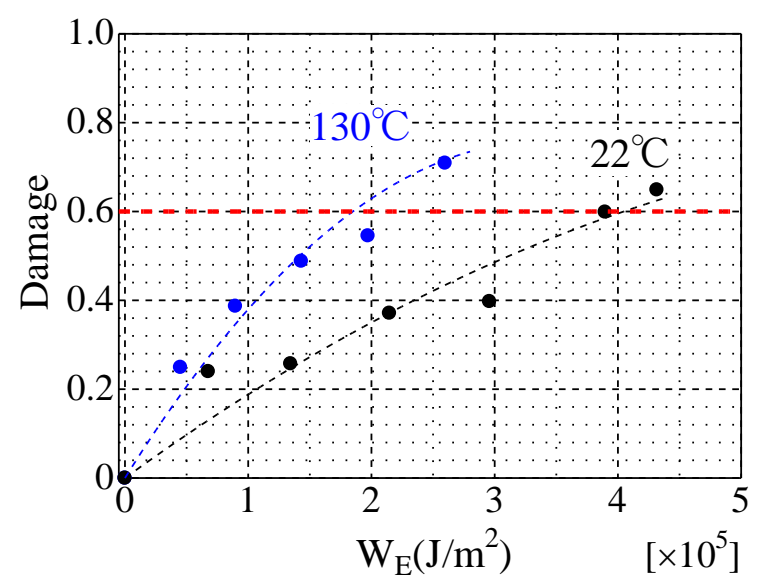

Fig. 8. Kinetic energy of impact-damage curve for PTFE fiber $\left(90^{\circ}\right)$

Figure 8 plots the relationship between $W_{E}$ and the damage of the PTFE fiber. The impact angle is $90^{\circ}$. The horizontal axis is the kinetic energy of impact $\left(\mathrm{W}_{\mathrm{E}}\right)$. As $\mathrm{W}_{\mathrm{E}}$ increases, fiber damage increases; and the increases of fiber damage are related to the temperature during erosion.

The erosion resistance of fibrous materials and their composites can be determined from Damage- $\mathrm{W}_{\mathrm{E}}$ (Fig. 8 ), but we evaluate the erosion resistance of fibrous materials and their composites using the sum of kinetic energy of the powder that is required to give a certain degree of damage to the material in order to compare the erosion resistances of various types of fibrous materials and their composites in an easy-to-understand manner. Here, the sum of the kinetic energy of the powder required to produce a specimen damage rate of 0.6 is defined as damage energy $\mathrm{y}_{0.6}, \mathrm{~J} / \mathrm{m}^{2}$. Figure 9 graphs the relationship between damage energy $y_{0.6}$ and the impact angle at different temperatures. Here, - represents the measured values at $22^{\circ} \mathrm{C}$, represents those at $130^{\circ} \mathrm{C}$, 
and $\boldsymbol{\Delta}$ represents those at $250^{\circ} \mathrm{C}$. Until the damage rate of the specimen reaches 0.6, PTFE fiber, a polymer fiber, requires more kinetic energy of powder (damage energy0.6) at higher impact angles than at lower impact angles. This result indicates that the erosion resistance of PTFE fiber at a higher impact angle is better than at a lower impact angle. As expressed in Eq. (2), the sum of the kinetic energy of powder includes the collision speed of powder, volume of powder per unit area, and wear time; thus, the degree of their influence can be estimated from the curves of damage energy 0.6 in Fig. 9. Furthermore, the erosion resistance of fiber decreases as the ambient temperature during erosion increases. With this method, measurement becomes more difficult as dispersion increases when the testing temperature increases from $250^{\circ} \mathrm{C}$ to the melting point of fiber $\left(327^{\circ} \mathrm{C}\right)$.

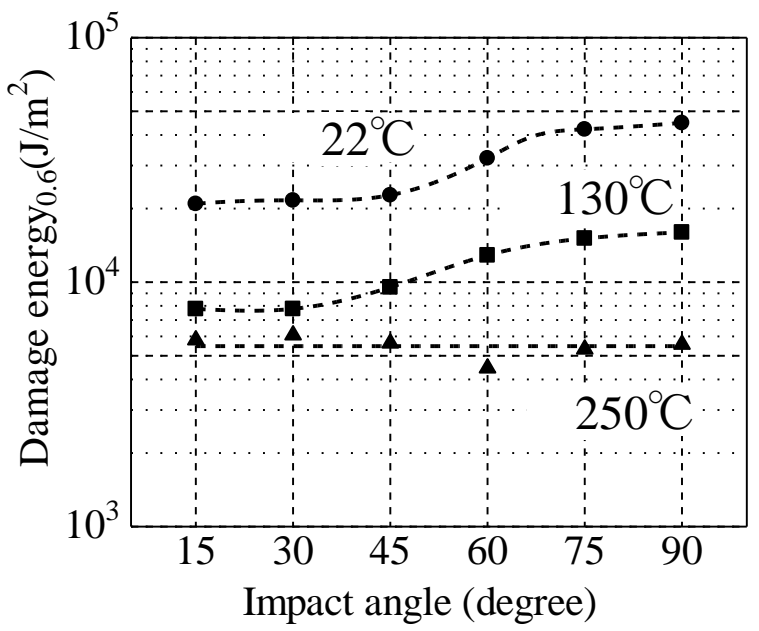

Fig. 9. Comparison of damage energy 0.6 at various Impact angles for PTFE fiber.

Figure 10 plots the relationship between damage energy $\mathrm{y}_{0.6}$ and ambient temperature during erosion. The specimen is PTFE fiber, and the impact angles are $30^{\circ}, 60^{\circ}$, and $90^{\circ}$. At each impact angle, erosion resistance decreases as ambient temperature increases. The gradient of the curve indicates the erosion resistance of each fiber.

Figure 11 graphs damage energy 0.6 vs. ambient temperature for PTFE fiber and glass fiber during erosion at various temperatures. As indicated by the curve gradients, damage energy 0.6 of glass fiber decreases more steeply than that of PTFE fiber. The erosion resistance of glass fiber is lower than that of PTFE fiber, a polymer fiber, at room temperature. Moreover, the decrease in erosion resistance is steeper in a hot environment. These results indicate the erosion types of various materials, which are useful as references for exploring the erosion mechanisms in fibrous materials. We will report the details of erosion mechanisms in fibrous materials in a hot environment in the next report.

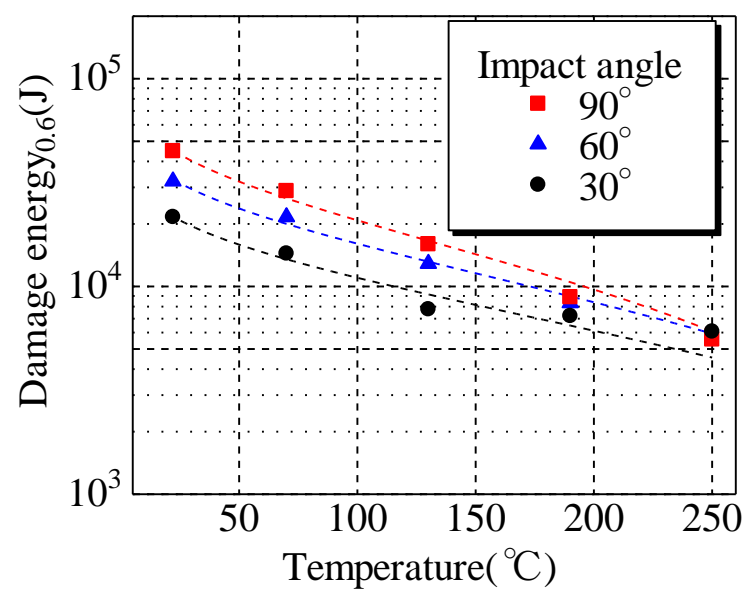

Fig. 10. Comparison of damage energy $\mathrm{y}_{0.6}$ at various temperatures for PTFE fiber.

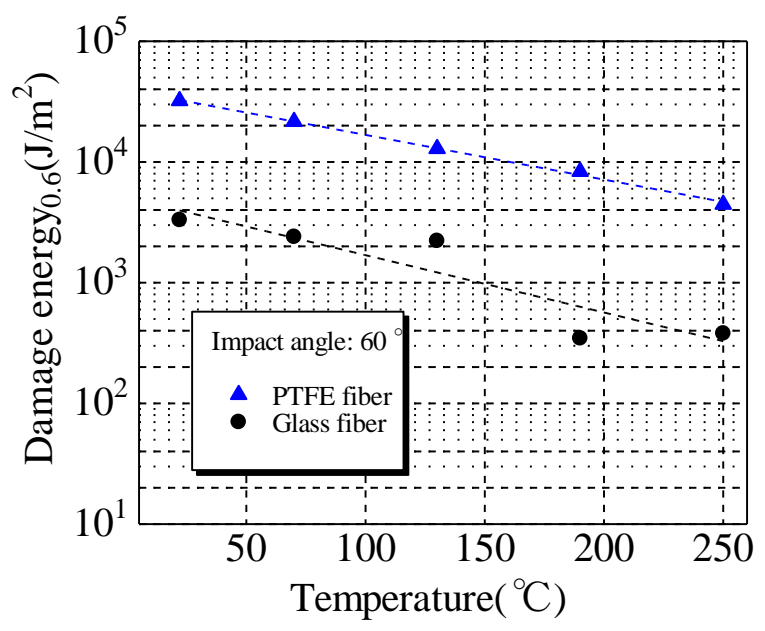

Fig. 11. Comparison of damage energy 0.6 at various temperatures for PTFE fiber and glass fiber (Impact angle: $60^{\circ}$ ).

\section{CONCLUSION}

To understand the dry sand erosion of fibrous materials in a hot environment, we proposed a method for evaluating the erosion resistance of materials by 
measuring the degree of reduced tensile fracture stress due to erosion.

Utilizing the proposed erosion measuring device in a hot environment enables the reproduction of the state of erosion of fibrous materials in a hot environment. The measured damage-energy value enables the evaluation of the influences of temperature and impact angle on the erosion resistance of fibrous materials.

\section{ACKNOWLEDGMENTS}

This work was supported by a Grant-in-Aid for Scientific Research (C) 215600857 from the Ministry of Education, Culture, Sports, Science, and Technology of Japan.

\section{REFERENCES}

1. Association of Powder Process Industry and Engineering Japan, Technology and Apparatus of Dust-Collection, NIKKAN KOGYO SHIMBUN,LTD., 2001, P87-99.

2. T. KISHIMA, L. BAO and K. NAKAZAWA, Experimental study about particle wear of the bag filters, Society of powder technology of JAPAN proceedings, PP.55-57(2003).

3. Kenji Hashimoto, Wear Resistance Designing of Particulate, Powder Science and Engineering, P122-128, (1987).

4. Kouji Kimura and Heihatiro Okabe; Introduction to Tribolog, YOKENDO Inc., 1982, P178-191.

5. A.P. Harsha, U.S. Tewari, B. Venkatraman, Solid particle erosion behaviour of various polyarylether- ketone composites, Wear, 254, 693-712 (2003).

6. A. Häger, K. Friedrich, Y.A. Dzenis, S.A. Paipetis, Study of erosion wear of advanced polymer composites, in: K. Street, B.C. Whistler (Eds.), Proceedings of the ICCM-10, Canada Woodhead Publishing Ltd., Cambridge, 1995, PP. 155-162.

7. QIAN Danna, BAO Limin, TAKATERA Masayuki, KEMMOCHI Kiyoshi, Particle Erosion Behavior of Unidirectional CF and GF Hybrid Fiber Reinforced Plastic Composites, Journal of Textile Engineering, Vol.55, No.2, 39-44(2009)

8. Danna Qian, Limin Bao, Masayuki Takatera, Kiyoshi Kemmochi and Atsuhiko Yamanaka, Fiber-reinforced polymer composite materials with high specific strength and excellent solid particle erosion resistance, Wear, Volume 268, Issues 3-4, 4 February 2010, Pages 637-642

9. Limin BAO, Yasuyuki Sato, Danna QIAN, Satoshi Simakawa, Zhijuan Pan and Shigeru Hinata, Dry Sand Erosion Damage Characteristic of Fibers Induced by Solid Particle Impact, Textile Research Journal ,Volume 80, 1675-1681 (2010). 